Terr. Atmos. Ocean. Sci., Vol. 18, No. 4, 843-856, October 2007

\title{
First Ground Observations of OI5577 Green Line Emission over the Taiwan Area
}

\author{
Sing-Wei Chiou ${ }^{1}$, Lin-Ni Hau ${ }^{1}{ }^{*}$, Jan-Bai Nee ${ }^{2}$, Chun-Sung Jao ${ }^{1}$, Bo-Jhou Wang ${ }^{1}$, \\ Yan-Fu Chen ${ }^{1}$, Wai-Leong Teh ${ }^{1}$, Shi-Hao Chuang ${ }^{1}$, Kuang-Wu Lee ${ }^{1}$, \\ Yu-Chieh Chou ${ }^{1}$, Yan-Ting Lai ${ }^{1}$, and Wei-Zhong Fu ${ }^{1}$
}

(Manuscript received 30 October 2006, in final form 5 March 2007)

\begin{abstract}
Worldwide ground observations of upper atmospheric airglow with particular emphasis on the OI 557.7 and $630 \mathrm{~nm}$ emissions have been conducted since 1960s. This study reports the first ground observations of OI $557.7 \mathrm{~nm}$ green line emission over the Taiwan area. For comparison, the background continuum at $530 \mathrm{~nm}$ was also measured by the same system. The experiments were conducted during the period of Aug - Dec, 2004 at various locations in Taiwan using a self-developed photometer instrument. Daily height integrated intensity of the night-time green line emission may vary in the range of 80 - 210 Rayleighs and twilight enhancement is also identified. The observational results may serve as a useful reference for follow-up sounding rocket measurements of OI $557.7 \mathrm{~nm}$ airglow emission over the Taiwan area.
\end{abstract}

(Key words: Airglow, OI 5577, Taiwan area, Ground observation)

\section{INTRODUCTION}

The observation of OI $557.7 \mathrm{~nm}$ airglow (hereafter referred to as OI5577) has been a primary information source for atomic oxygen variation in the atmosphere. The sources of

\footnotetext{
${ }^{1}$ Institute of Space Science, National Central University, Chung-Li, Taiwan, ROC

2 Department of Physics, National Central University, Chung-Li, Taiwan, ROC

* Corresponding author address: Prof. Lin-Ni Hau, Institute of Space Science, National Central University, Chung-Li, Taiwan, ROC; E-mail: Inhau@jupiter.ss.ncu.edu.tw doi: 10.3319/TAO.2007.18.4.843(AA)
} 
OI5577 green line are excited oxygen atoms $\mathrm{O}\left({ }^{1} \mathrm{~S}\right)$ which may originate from two different regions of the atmosphere. In the thermosphere or the ionospheric $\mathrm{F}$ region of about $250 \mathrm{~km}$, excited oxygen atoms $\mathrm{O}\left({ }^{1} \mathrm{~S}\right)$ are produced by the recombination of ionized molecular oxygen $\left(\mathrm{O}_{2}^{+}\right)$with electrons:

$$
\begin{aligned}
& \mathrm{O}_{2}^{+}+e^{-} \rightarrow \mathrm{O}+\mathrm{O}\left({ }^{1} \mathrm{~S}\right), \\
& \mathrm{O}\left({ }^{1} \mathrm{~S}\right) \rightarrow \mathrm{O}+h v(557.7 \mathrm{~nm}),
\end{aligned}
$$

(e.g., Nicolet 1954; Chamberlain and Hunten 1987). Whereas, in the upper mesosphere or the ionospheric E region of about $95 \mathrm{~km}$, excited oxygen atoms $\mathrm{O}\left({ }^{1} \mathrm{~S}\right)$ may be produced by the socalled Barth mechamism:

$$
\begin{aligned}
& \mathrm{O}+\mathrm{O}+\mathrm{M} \rightarrow \mathrm{O}_{2}^{*}+\mathrm{M}, \\
& \mathrm{O}_{2}^{*}+\mathrm{O} \rightarrow \mathrm{O}_{2}+\mathrm{O}\left({ }^{1} \mathrm{~S}\right), \\
& \mathrm{O}\left({ }^{1} \mathrm{~S}\right) \rightarrow \mathrm{O}+h v(557.7 \mathrm{~nm})
\end{aligned}
$$

(Barth and Hildebrandt 1961), for which $\mathrm{M}$ is $\mathrm{N}_{2}$ and/or $\mathrm{O}_{2}$, and $\mathrm{O}_{2}^{*}$ is the electronically excited state of $\mathrm{O}_{2}$ and the precursor leading to $\mathrm{O}\left({ }^{1} \mathrm{~S}\right)$. However, the details of the excitation processes of the emissions are still not fully understood. For a review on this subject, readers are referred to the papers by Bates (1981), Torr (1985), McDade and Llewellyn (1986), and Meriwether (1989) where several reaction mechanisms for atomic oxygen OI5577 emission were suggested with the Barth mechamism (Barth and Hildebrandt 1961) being the most widely discussed one.

Observation of airglow began nearly six decades ago and can be made by means of ground based instruments or payloads onboard balloons, rockets or satellites. Different approaches to measurement contain different kinds of information; in particular, the results of ground-based or satellite observations are integrated intensities of the column emission rate while rocket experiments conduct in-situ measurements that can give rise to the altitude profile of the airglow volume emission rate (e.g., Gulledge et al. 1968; Ogawa et al. 1987; Takahashi et al. 1987, 1996; Kita et al. 1988, 1992). In the early phase of instrument development, simple photocathodes, spectrographs or spectrometers were used to study the emission lines of airglows in a qualitative way (e.g., Elvey 1942). Later the development of the photomultiplier made accurate observation of airglow possible. Even nowadays many ground-based, rocket or satellite observations still rely on the photomultiplier-based photometer. After the 1990s the development of high quantum efficiency CCD made simultaneous two-dimensional observations simpler and all-sky airglow imaging a useful method for investigating the dynamics of the emission layer. In our study, a photomultiplier-based photometer is developed to conduct ground observation of OI5577 emission over the Taiwan area.

There have been many studies (e.g., Colerico et al. 1996; Angelats i Coll and Forbes 1998; Balan et al. 2004; Brown et al. 2004; Smith et al. 2006) that utilize the information of OI5577 airglow to deduce the dynamics and structure of the E region or F region of the iono- 
sphere (upper mesosphere or thermosphere). Weinberg and Mann (1967) of the University of Hawaii conducted the first systematic sky-scanning measurements of OI5577 airglow and other wavelength bands at Mt. Haleakala Maui, Hawaii (geographic longitude of $156.6^{\circ} \mathrm{N}$ and latitude of $20.7^{\circ} \mathrm{N}$, and altitude of $3033 \mathrm{~m}$ ) in the early $1960 \mathrm{~s}$ to provide a basic reference database for balloon, rocket and satellite observations. Kim et al. (2002) reconstructed the projected maps of the airglow distributions at $\mathrm{F}$ region altitude from the database and identified the equatorial spread $\mathrm{F}$ by OI5577 and OI $630.0 \mathrm{~nm} \mathrm{O}\left({ }^{1} \mathrm{D}\right)$ (hereafter referred to OI6300) observations. Hickey et al. (1993, 1998, 2001) and Schubert et al. (1999) investigated the intensity fluctuations of the OI5577 from airglow image and found that the fluctuations can be interpreted as the gravity waves propagating through the emission layer at $90-100 \mathrm{~km}$. The F region plasma depletion phenomenon, so-called plasma bubbles, around $300 \mathrm{~km}$ can also be seen via the observations of OI5577 and OI6300 emissions. Takahashi et al. (2001) used groundbased two-dimensional imaging of airglow OI5577 and OI6300 emissions to show the fine structure of the plasma bubble and pointed out that OI5577 can show more of the fine structure of the bubble than OI6300 emission.

The long-term variation of OI5577 is also an important topic of study. Deutsch and Hernandez (2003) collected large amounts of data that encompass observations from different stations at low geomagnetic activity from 1923 to 2003 and carried out long-term time series analysis. The longest time series provided by their study is about 12 years. The result shows that the OI5577 emission rate increases with solar activity in general; in particular, the emission rate is higher during the decreasing phase of solar activity but it has apparent changes in different solar cycles and latitudinal dependence. The annual and semiannual variations also provide seasonal behavior of OI5577 emission. In general, analysis shows a maximum during autumn and minimum near the spring equinox, but the detailed behavior strongly depends on the latitude. Latitudinal dependence indicates that the emission rate increases with latitude and this result has been confirmed in many other reports (e.g., Donahue et al. 1973; Cogger et al. 1981; Shepherd et al. 1999). However, investigations of daily variation of OI5577 do not show clear characteristics pertaining to maxima or minma during daily observation. Some of the studies show the presence of a general maximum near midnight (e.g., Christophe-Glaume 1965), but others do not show the same behavior (Smith and Steiger 1968). Some studies also show a correlation between geomagnetic activity and the OI5577 emission rate (e.g., Silverman 1970; Hernandez 1976); in particular, during high geomagnetic activity, measured by the Kp index, enhanced auroral activity and thermospheric temperature may contribute to the OI5577 emission rate.

Chow et al. (2002) reported coincident observations of equatorial bubbles by ROCSAT-1 (FORMOSAT-1) spacecraft and the OI6300 airglow ground imager at Mt. A-Li, Taiwan $\left(23.3^{\circ} \mathrm{N}\right.$, $120.5^{\circ} \mathrm{E}$ ). But reference information regarding quantitative measurement of OI5577 in the Taiwan area is still lacking. This paper presents the first quantitative OI5577 green line observation over the Taiwan area based on a self-developed photometer instrument. The objective of the observations is to provide basic references for follow-up sounding rocket experiments or all-sky imager observations of OI5577 emission in the Taiwan area. Most of our observations were conducted throughout the night including the twilight period; i.e., the transition from night to day. During twilight the atmosphere is illuminated gradually by the Sun with a 
decreasing solar zenith angle, and the effect of photon ionization can be investigated in this period. Attempts have been made to find the relation between solar radiation and OI5577 emission during twilight (e.g., Megill 1960; Deehr 1969; Hays and Sharp 1973) but the existence and mechanism of OI5577 twilight enhancement was not revealed explicitly until the work of Schaeffer (1975) who has attributed the enhancement to the dissociative recombination of $\mathrm{O}_{2}{ }^{+}$ with electrons in the ionospheric F region. Schaeffer's results imply that seasonal variation, daily variation and activities of the F region are related to OI5577 twilight enhancement. In this paper, we also show a qualitative result of twilight enhancement from our preliminary ground observations of OI5577 emission over the Taiwan area.

\section{INSTRUMENTATION}

The instruments used in this study are two independent photometer systems that were designed and developed by the Satellite Payload Development Laboratory of the Institute of Space Science, National Central University. The optical sensors of the system are designed for two wavelength bands: 530.0 and $557.7 \mathrm{~nm}$; each consisting of a band pass interference filter, a synthetic fused silica lens, and a photomultiplier. The photomultiplier utilizes the photoncounting method to detect photons emitted from the airglow. The half bandwidth (FWHM) is $1 \mathrm{~nm}$ for both interference filters and the field of view (FOV) of the photometers is $4.7^{\circ}$ circular in full angle for visible light. The two photometers are installed side by side to align the field of view of both photometers along zenith and to reduce the inaccuracy arising from spatial inhomogenity.

The photometers were absolutely calibrated with a standard light source available at the National Precision Instrument Development Center of Taiwan. The sensitivity of the system is $25 \mathrm{cps} \mathrm{R}^{-1}$ (cps = counts per second; $\mathrm{R}=$ Rayleigh; $1 \mathrm{R}=10^{6}$ photons $/ \mathrm{sec}-\mathrm{cm}^{2}$ ). The uncertainty of measurement is governed by systematic errors (associated with quantum efficiency of detector, transmission rate of filter, FOV and calibration errors etc.), random errors (due to thermal noise and dark counts etc.), and dynamic errors (associated with the dynamic properties of the instrument, setting time and time constant etc.). In our photometer system, the uncertainty of the measurement is dominated by shot noise and linearity of the system's response. On average, the measurement uncertainty for our photometer system is $7.3 \sim 14.9 \mathrm{R}$ for the range of $50 \sim 210 \mathrm{R}$.

\section{OBSERVATIONS}

Since there is no special emission line associated with $530 \mathrm{~nm}$, the measurement results of the $530 \mathrm{~nm}$ photometer can be used as reference guide to the background continuum from light pollution or any astronomical background feature that may cause contamination of the OI5577 green line measurement. In general, cloud or fog may reflect or scatter light pollution or block airglow emission of the night sky, and moonlight may cause an appreciable background continuum, therefore a clear sky and new moon period conditions are required for groundbased airglow observations to prevent contamination due to other light sources. 
The first successful benchmark experiment was carried out at Chung-Li $\left(25^{\circ} \mathrm{N}, 121.2^{\circ} \mathrm{E}\right)$ on 17 August 2004 and the results are shown in Fig. 1. The sunset/sunrise time was at 1828/ $0528 \mathrm{LT}$ and the moonrise/moonset time was at 0617/1927 LT (new moon period) on the day of observation. Measurement lasted only for about half an hour due to cloud appearing in the night sky and rain over the following days. Figure 1a shows the intensities of OI5577 emission and $530 \mathrm{~nm}$ background continuum and the average intensities are 8648 and $4671 \mathrm{cps}$, respectively. In Fig. 1b, the continuum background has been subtracted from the OI5577 and the unit of the intensity is also converted to Rayleigh (R). Since the value shows the integrated intensity, it represents the column emission rate of OI5577. The average column emission rate of OI5577 is about $160 \mathrm{R}$ in this observation.

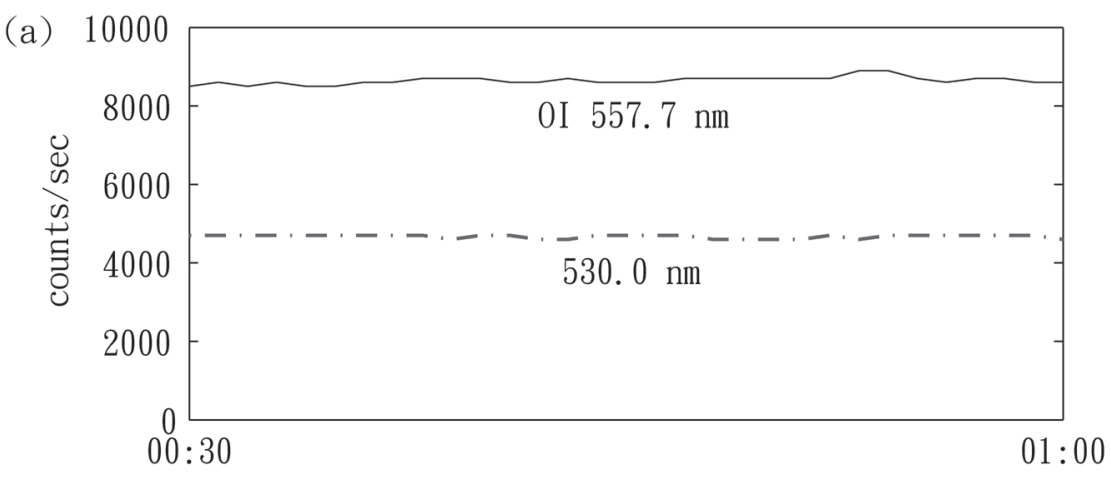

LOCAL TIME

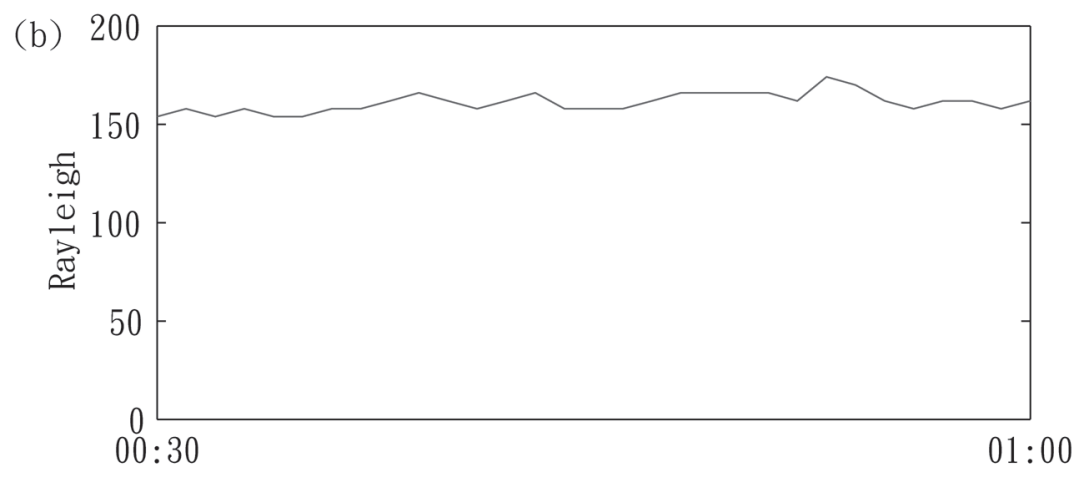

LOCAL TIME

Fig. 1. (a) The intensity variations of the $530 \mathrm{~nm}$ background continuum and OI5577 emissions. (b) The column emission rate of the OI5577 deduced from Fig. 1a. The observation was carried out at Chung- $\mathrm{Li}\left(25^{\circ} \mathrm{N}, 121.2^{\circ} \mathrm{E}\right)$ on 17 August 2004. 
Figure 2 shows a successful all night observation of intensity variation of $530 \mathrm{~nm}$ and OI5577 emissions at Chung-Li $\left(25^{\circ} \mathrm{N}, 121.2^{\circ} \mathrm{E}\right)$ on 21 September 2004. The sunset/sunrise was at 1751/0542 LT, and the moonrise/moonset was at 1213/2149 LT. We measured the emissions of OI5577 and $530 \mathrm{~nm}$ background continuum simultaneously with a data sampling rate of 1 sample $\min ^{-1}$, and an operating period from midnight to dawn. Figure 2a shows that the trends of intensities for these two bands are similar in that both decrease before twilight appears at around $0440 \mathrm{LT}$ (solar zenith angle of $\sim 104^{\circ}$ ). But after $0440 \mathrm{LT}$ the intensity of these two bands increases drastically with increasing twilight. The minimum intensity of the $530 \mathrm{~nm}$ background continuum and OI5577 emissions are at $0318 \mathrm{LT}$ (solar zenith angle of $\sim 126^{\circ}$ ) and $0433 \mathrm{LT}$ (solar zenith angle of $\sim 106^{\circ}$ ), respectively. There are two curves in panel (b) of Figs. 2, 4, 5, and 6, for which the solid curves are OI5577 subtracted by the $530 \mathrm{~nm}$ emissions and the dashed curves are the corrected OI5577 emissions to show twilight enhancement as explained in the discussion section. Aside from the twilight enhancement both curves are the same. In this section, we shall focus on night emission and discuss only emission features prior to twilight enhancement. Figure $2 \mathrm{~b}$ shows that the OI5577 column emission rate is of $\sim 160 \pm 20 \mathrm{R}$, similar to the case shown in Fig. 1. The average is of $\sim 160 \mathrm{R}$ before $0330 \mathrm{LT}$, and the peak value is of $\sim 180 \mathrm{R}$ at $0140 \mathrm{LT}$. It can be seen that OI5577 emission decreases after $0330 \mathrm{LT}$ until twilight appears around $0440 \mathrm{LT}$, and the background continuum is even larger than OI5577 after $0500 \mathrm{LT}$ (solar zenith angle of $\sim 101^{\circ}$ ).
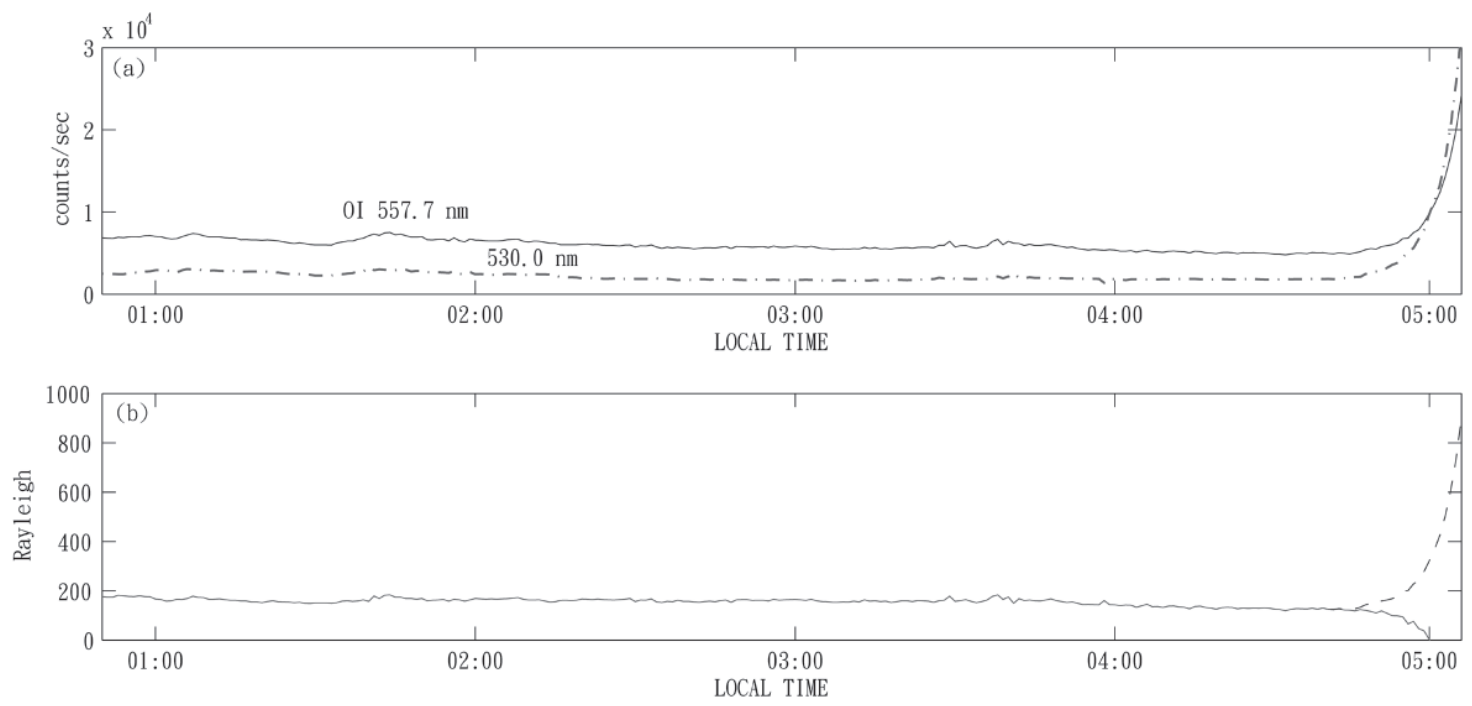

Fig. 2. (a) The intensity variations of the $530 \mathrm{~nm}$ background continuum and OI5577 emissions observed at Chung-Li on 21 September 2004. (b) The column emission rate of the OI5577 deduced from Fig. 2a. The dashed curve in panel (b) is the twilight enhancement of OI5577 emission. 
For comparison, Fig. 3 shows an example of the observations conducted on 29 September 2004 during a full moon period at Chung- $\mathrm{Li}\left(25^{\circ} \mathrm{N}, 121.2^{\circ} \mathrm{E}\right)$, indicating that the intensities of OI5577 emission and $530 \mathrm{~nm}$ background continuum increase drastically with the increasing zenith angle of moon. The moonrise/moonset time was at 1816/0609 LT on that day and the zenith angle of the moon moved from $64^{\circ}$ to $41.5^{\circ}$ in the period of 2000 to $2130 \mathrm{LT}$. As compared to the previous two cases conducted during new moon periods, the emissions for both bands are much stronger and the $530 \mathrm{~nm}$ even dominates the OI5577 emission after $2030 \mathrm{LT}$. Substracting the background continuum will lead to a negative value for OI5577 emission. Such measurement thus cannot be used to deduce the green line emission of night airglow.

Figure 4 shows an example of observations conducted at Mu-Dan $\left(22.2^{\circ} \mathrm{N}, 120.8^{\circ} \mathrm{E}\right)$ of southern Taiwan on 11 October 2004. The overall profile of counting rate versus local time is similar to the cases conducted at Chung-Li, but the absolute emission rates for both 530 and $557.7 \mathrm{~nm}$ are smaller than those obtained at Chung-Li; in particular, the peak emission rate of OI5577 after substracting the background $530 \mathrm{~nm}$ is about $80 \mathrm{R}$. The discontinuties in the data shown in Fig. 4 are the dark-count checking points of the system. Figure 5 shows another example of observations conducted on 13 October 2004 at Chung-Li and the periodic discontinuities are dark-count checking points which shows that after a long period of operation the system still has very low dark counts $\left(<25 \mathrm{counts} \mathrm{sec}^{-1}\right)$. Note that the jump in the emission rate from 0355 to 0415 is due to reflection in light pollution from overhead passing clouds.

Figure 6 shows an observation conducted on 11 November 2004 at Gau-Yi $\left(24.7^{\circ} \mathrm{N}\right.$, $121.4^{\circ} \mathrm{E}$ ) of northern Taiwan and the data gaps from 0040 to 0105 are due to overhead passing clouds, rain and system checking. The profile of the count rate versus local time is different from that of previous cases in that the peak emission rate occurs at $0500 \mathrm{LT}$ in this case. Table 1 lists all the successful ground observation cases for OI5577 emission in the Taiwan area during

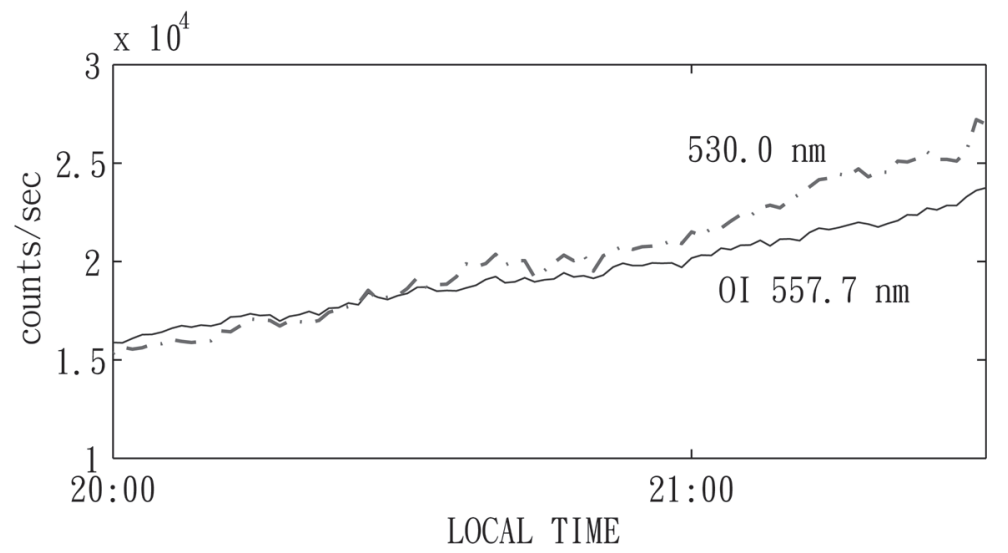

Fig. 3. The intensity variations of the $530 \mathrm{~nm}$ background continuum and OI5577 emissions observed at Chung-Li on 29 September 2004. 

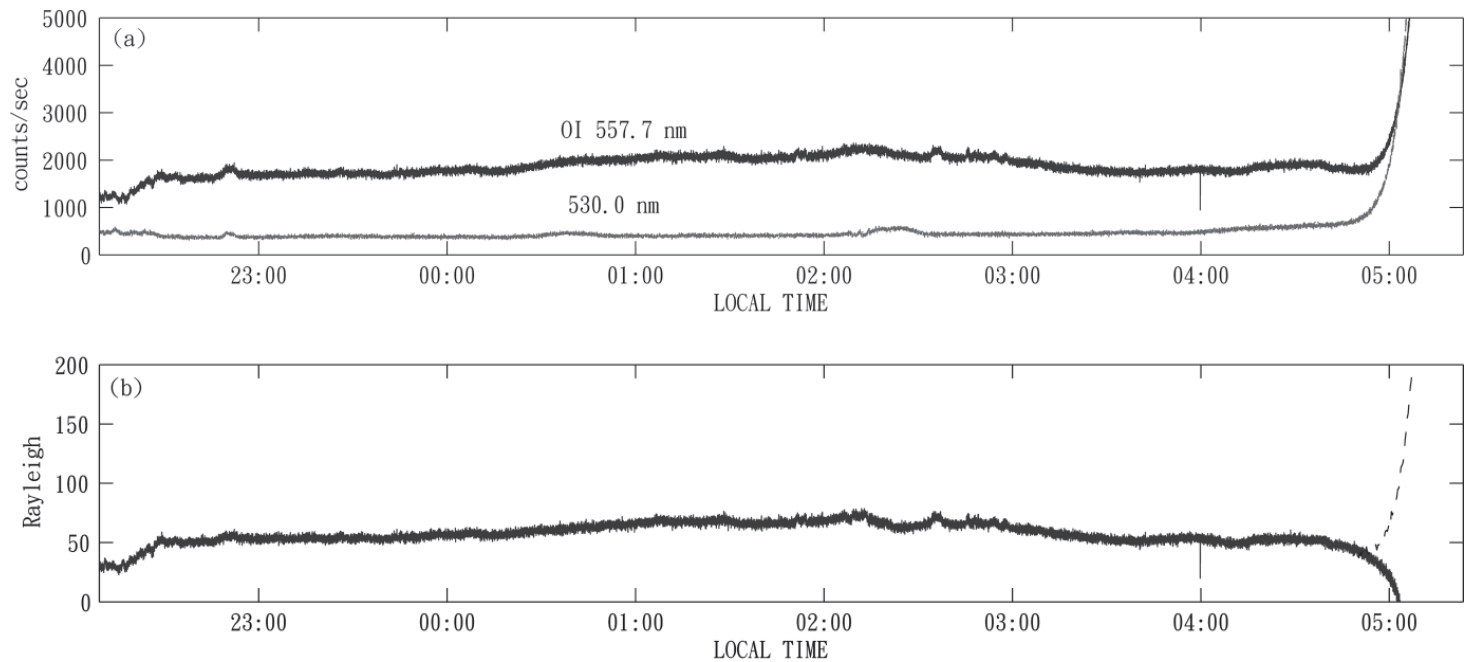

Fig. 4. (a) The intensity variations of the $530 \mathrm{~nm}$ background continuum and OI5577 emissions observed at Mu-Dan $\left(22.2^{\circ} \mathrm{N}, 120.8^{\circ} \mathrm{E}\right)$ on 11 October 2004. (b) The column emission rate of the OI5577 deduced from Fig. 4a. The dashed curve in panel (b) is the twilight enhancement of OI5577 emission.
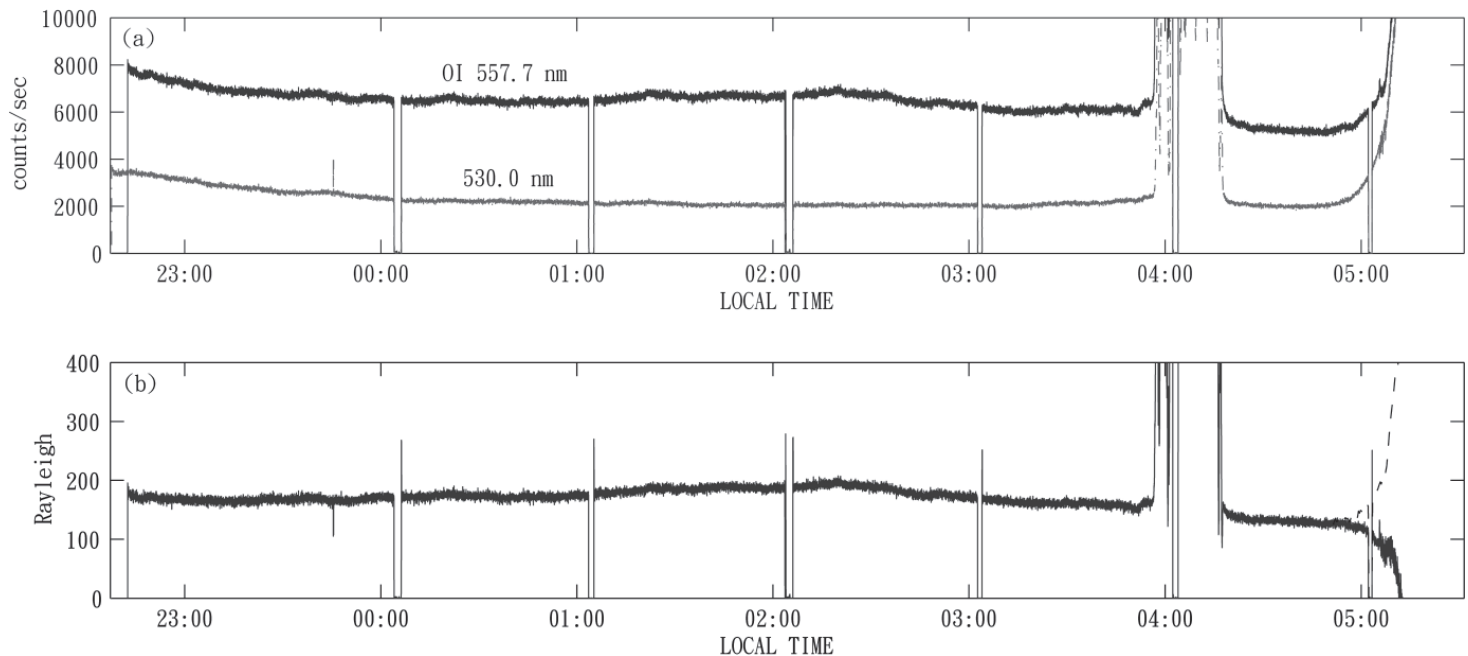

Fig. 5. (a) The intensity variations of the $530 \mathrm{~nm}$ background continuum and OI5577 emissions observed at Chung-Li on 13 October 2004. (b) The column emission rate of the OI5577 deduced from Fig. 5a. The dashed curve in panel (b) is the twilight enhancement of OI5577 emission. The data gaps are due to system checking. 

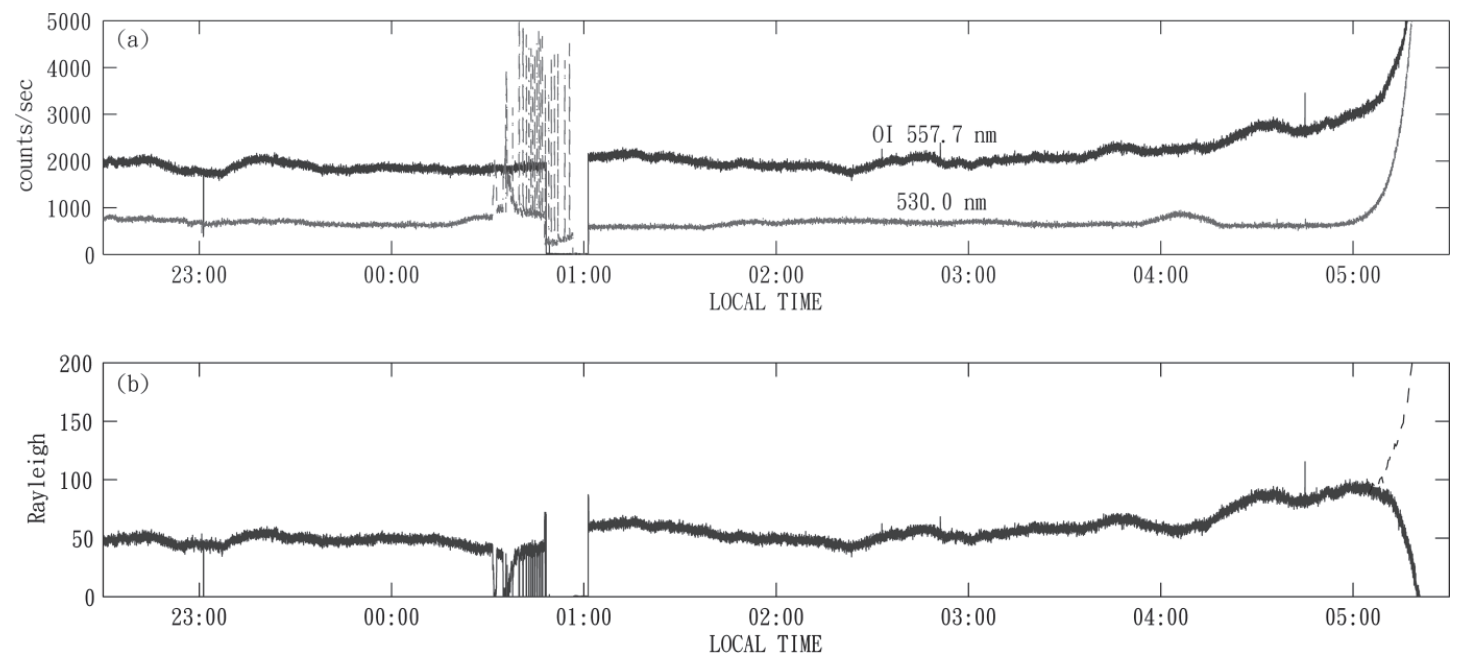

Fig. 6. (a) The intensity variations of the $530 \mathrm{~nm}$ background continuum and OI5577 emissions observed at Gau-Yi $\left(24.7^{\circ} \mathrm{N}, 121.4^{\circ} \mathrm{E}\right)$ on 11 November 2004. (b) The column emission rate of the OI5577 deduced from Fig. 6a. The dashed curve in panel (b) is the twilight enhancement of OI5577 emission.

Table 1. Observational cases of OI5577 emissions in the Taiwan area during 2004.

\begin{tabular}{|c|c|c|c|c|c|c|c|}
\hline \multirow[t]{2}{*}{ Location } & \multirow[t]{2}{*}{ Date } & \multirow[t]{2}{*}{$\begin{array}{c}\text { Maximum overhead } \\
\text { intensity (R) of OI5577 } \\
\text { emissions }\end{array}$} & \multicolumn{5}{|c|}{$\begin{array}{c}\text { Kp index } \\
\text { (Local Time) }\end{array}$} \\
\hline & & & 20 & --23 & --02 & --05 & $--\quad 08$ \\
\hline Chung-Li $\left(25^{\circ} \mathrm{N}, 121.2^{\circ} \mathrm{E}\right)$ & Sep 21 & $180 \mathrm{R}(0140 \mathrm{LT})$ & & 3. & 2 o & $0_{+}$ & $1_{+}$ \\
\hline $\mathrm{Mu}-\operatorname{Dan}\left(22.2^{\circ} \mathrm{N}, 120.8^{\circ} \mathrm{E}\right)$ & Oct 10 & $75 \mathrm{R}(2200 \mathrm{LT})$ & & $2_{\mathrm{o}}$ & 1. & $1_{+}$ & 2 o \\
\hline $\mathrm{Mu}-\operatorname{Dan}\left(22.2^{\circ} \mathrm{N}, 120.8^{\circ} \mathrm{E}\right)$ & Oct 11 & $80 \mathrm{R}(0230 \mathrm{LT})$ & & $2+$ & $2+$ & 2. & $3_{+}$ \\
\hline $\mathrm{Mu}-\operatorname{Dan}\left(22.2^{\circ} \mathrm{N}, 120.8^{\circ} \mathrm{E}\right)$ & Oct 12 & $120 \mathrm{R}(0350 \mathrm{LT})$ & & 1. & 1. & 1. & $3_{+}$ \\
\hline Chung-Li $\left(25^{\circ} \mathrm{N}, 121.2^{\circ} \mathrm{E}\right)$ & Oct 13 & $200 \mathrm{R}(0220 \mathrm{LT})$ & & $5_{\mathrm{o}}$ & $4_{\mathrm{o}}$ & $4_{\mathrm{o}}$ & $3_{+}$ \\
\hline Chung-Li $\left(25^{\circ} \mathrm{N}, 121.2^{\circ} \mathrm{E}\right)$ & Oct 14 & $200 \mathrm{R}(2310 \mathrm{LT})$ & & $4_{+}$ & $4_{0}$ & 4. & $2_{+}$ \\
\hline Chung-Li $\left(25^{\circ} \mathrm{N}, 121.2^{\circ} \mathrm{E}\right)$ & Nov 09 & $210 \mathrm{R}(0250 \mathrm{LT})$ & & 7. & 7. & 9. & $7 \%$ \\
\hline Gau-Yi $\left(24.7^{\circ} \mathrm{N}, 121.4^{\circ} \mathrm{E}\right)$ & Nov 11 & $100 \mathrm{R}(0500 \mathrm{LT})$ & & $2_{+}$ & $3_{0}$ & $2_{+}$ & $4_{+}$ \\
\hline Chung-Li $\left(25^{\circ} \mathrm{N}, 121.2^{\circ} \mathrm{E}\right)$ & Nov 12 & $130 \mathrm{R}(0140 \mathrm{LT})$ & & $3_{+}$ & $4_{\mathrm{o}}$ & $4_{+}$ & $4_{0}$ \\
\hline
\end{tabular}


2004. The listed emission rate is the maximum intensity for each case prior to twilight enhancement. Note that the experiments were performed in the later half of the year because weather conditions were not sutible for airglow observations over spring and summer in the Taiwan area during 2004.

\section{DISCUSSION AND SUMMARY}

As indicated in Table 1, the peak integrated intensity of nocturnal OI5577 emission for each observed case over the Taiwan area is in the range of $80-210 \mathrm{R}$. The statistical results of worldwide airglow observations during the International Geophysical Year and the International Geophysical Cooperation, 1957 - 1959, (Yao 1962) and other later statistical results obtained, for example, by Deutsch and Hernandez (2003) show that the intensities of OI5577 emissions may vary from $\sim 20$ to $\sim 600 \mathrm{R}$. Our observational results of OI5577 appear to be in the statistical range. As mentioned above, OI5577 emissions may come from the thermosphere (F region ionosphere) or upper mesosphere (E region ionosphere), thus emissions of oxygen atoms can increase significantly during the equatorial anomaly or high solar activity periods. Takahashi et al. (2001) pointed out that OI5577 emission intensity increased significantly and reached above $100 \mathrm{R}$ during the maximum phase of solar activity in 1998 - 1999.

The last column of Table 1 shows the Kp index during the observation. Each number and suffix represent a three-hour index; in particular, they are indices of 2000 - 2300 LT, 2300 0200 LT, 0200 - 0500 LT, and 0500 - 0800 LT, respectively. Although we have only limited observational cases, a comparison of the Kp index and the occurrence time of the peak emission rate shows that, in general, the peak value occurs in or near the period of the largest $\mathrm{Kp}$ index. The 13 October case shown in Fig. $5 \mathrm{~b}$ for OI5577 emission seems to be an exception for which the largest Kp occurs during 2000 - 2300 LT while the peak emission rate is at 0220 LT. Nevertheless absolute observed OI5577 emission without substracting the $530 \mathrm{~nm}$ emission still exhibits a peak emission rate before 2300 LT. This may be due to a large value for the background continuum $530 \mathrm{~nm}$ arising from severe city light pollution before midnight. Note that the maximum emission rate in our observations is on 9 November and that happens to be the period of a geomagnetic storm's sudden commencement though the magnetic storm is only one of the factors that may affect the variation of the OI5577 emission rate. Analysis of the long-term observation of OI5577 emission (Deutsch and Hernandez 2003) has indicated that local variations in atmospheric or ionospheric conditions also have significant effects on variation in the emission rate.

Schaeffer (1975) used the Fabry-Perot interferometer to measure OI5577 in the presence of an appreciable twilight background continuum and found that enhancement of OI5577 emanating from the dissociative recombination of $\mathrm{O}_{2}{ }^{+}$and electrons in the ionospheric $\mathrm{F}$ region begins at solar zenith angle of $\sim 106^{\circ}$. The intensity of the emission can even reach $\sim 1000 \mathrm{R}$ for solar zenith angle of $96^{\circ} \sim 100^{\circ}$ in twilight. Since the twilight phenomenon is governed by various factors, such as, the solar irradiance spectrum, shadow of the Earth, and atmospheric effects, including scattering, reflection, and absorption, the critical issue for twilight enhancement measurement is the accurate subtraction of the background continuum. Schaeffer (1975) took measurements in both zenith and $75^{\circ}$ zenith angle during twilight and identified OI5577 
enhancement for both cases but pointed out that it is difficult to define the absolute value for the zenith case due to a strong sunlit scattered background. To improve the discrimination of the twilight airglow signal, observation should be conducted at a larger zenith angle in the sun's azimuth. In our experiments, all observations are conducted in the zenith direction, thus the background continuum is dominated by scattered sunlight during twilight. In Schaeffer's work, for the zenith observation, the intensity of OI5577 twilight enhancement is estimated simply by subtracting nightglow intensity that is assumed constant during the twilight period.

As shown in panel (a) of Figs. 2, 4, 5, and 6, there is an obvious twilight enhancement for both bands before sunrise; for example, in Fig. 2, the twilight enhancement for both bands begins from $0440 \mathrm{LT}$ when the solar zenith angle is about $\sim 104^{\circ}$. The 015577 emission after subtracting the $530 \mathrm{~nm}$, however, does not exhibit twilight enhancement due to the fact that the scattered background intensity of $530 \mathrm{~nm}$ is much higher than $557.7 \mathrm{~nm}$. Thus, it is not appropriate to use the simultaneous $530 \mathrm{~nm}$ wavelength band as a background continuum to deduce the twilight enhancement measurement of OI5577, as explained above. To estimate the OI5577 emission rate in an overwhelming solar scatter background, we adopt the same method as that of Schaeffer, i.e., we use the value of the $530 \mathrm{~nm}$ background continuum at a solar zenith angle of $\sim 108^{\circ}$, corresponding to $0426 \mathrm{LT}$ for the case shown in Fig. 2, as the sunlit background continuum. The results shown by the dashed curves in panel (b) of Figs. 2, 4, 5, and 6 indicate that the intensity of OI5577 emission may vary from 100 to $1000 \mathrm{R}$ during solar zenith angle of $\sim 104^{\circ}$ to $\sim 98^{\circ}$ (corresponding to $0440 \sim 0506$ LT in Fig. 2) which is qualitatively similar to Schaeffer's result even though the sunlight scattering condition of local aerosol and signal to background ratio of the instrument are different. A somewhat different method has also been made to estimate the background continuum obtained from our $530 \mathrm{~nm}$ observations. In particular, the estimation based on the intensity of solar irradiance and wavelength-dependent Rayleigh scattering shows that the zenith intensity of $530 \mathrm{~nm}$ is about 1.3 1.5 times larger than the intensity of $557.7 \mathrm{~nm}$. This result can in principle be used to estimate the $557.7 \mathrm{~nm}$ sunlit background during a twilight period that is about $0.67 \sim 0.77$ of $530 \mathrm{~nm}$ emission. The results show that OI5577 twilight enhancement may still occur but only when assuming $530 \mathrm{~nm}$ to be $\sim 1.5$ times larger than the intensity of $557.7 \mathrm{~nm}$. In this case, the onset of twilight enhancement occurs at slightly later times than those shown in the figures.

In summary, we have utilized a self-developed photometer instrument to conduct the first ground measurements of OI5577 emission at various locations within the Taiwan area during the period of August - December 2004. The results show that peak intensity of night time OI5577 emission is in the range of $80-210 \mathrm{R}$ and there exists a good correlation between emission and geomagnetic activity measured according to the Kp index. In addition, limited cases show a clear feature of twilight emission enhancement. Similar characteristics of OI5577 green line emission have been reported by other authors using data collected at various places in the world, implying that our measurements are mostly meaningful. The ground observational data reported here may serve as a useful reference to follow-up sounding rockets and the all sky imager as well as long-term ground measurements of night time OI5577 emission over the Taiwan area.

Acknowledgements This research is supported by the National Science Council of the Republic of China under grants NSC93-2111-M-008-009 and NSC95-2111-M-008-001, and by 
the National Space Organization under grant 93-NSPO(B)-SR4-FA07-01 to the National Central University.

\section{REFERENCES}

Angelats i Coll, M., and J. M. Forbes, 1998: Dynamical influences on atomic oxygen and $5577 \AA$ Å emission rate in the lower thermosphere. Geophys. Res. Lett., 25, 461-464.

Balan, N., S. Kawamura, T. Nakamura, M. Yamamoto, S. Fukao, K. Igarashi, T. Maruyama, K. Shiokawa, Y. Otsuka, T. Ogawa, H. Alleyne, S. Watanabe, and Y. Murayama, 2004: Simultaneous mesosphere/lower thermosphere and thermospheric F region observations during geomagnetic storms. J. Geophys. Res., 109, A04308, doi:10.1029/2003JA009982.

Barth, C. A., and A. F. Hildebrandt, 1961: The 5577 A airglow emission mechanism. J. Geophys. Res., 66, 985-986.

Bates, D. R., 1981: The green light of the night sky. Planet Space Sci., 29, 1061-1067.

Brown, L. B., A. J. Gerrard, and J. W. Meriwether, 2004: All-sky imaging observations of mesospheric front in OI $557.7 \mathrm{~nm}$ and broadband $\mathrm{OH}$ airglow emissions: Analysis of frontal structure, atmospheric background conditions, and potential sourcing mechanisms. J. Geophys. Res., 109, D19104, doi:10.1029/2003JD004223.

Chamberlain, J. W., and D. M. Hunten, 1987: Theory of planetary atmospheres: An introduction to their physics and chemistry. Int. Geophys. Ser., 36 ( $2^{\text {nd }}$ Ed. $)$, Academic, San Diego, 288.

Chow, T. C., H. Chou, H. C. Yeh, S. Y. Su, and C. H. Liao, 2002: Coincident observations of equatorial bubbles by ROCSAT-1 and a ground imager at southern Taiwan. Adv. Space Res., 30, 2569-2574.

Christophe-Glaume, J., 1965: Etude de la raie 5577 Å de l'oxygène dans la luminescence atmosphérique nocturne. Ann. Geophys., 21, 1-57.

Cogger, L. L., R. D. Elphinstone, and J. S. Murphree, 1981: Temporal and latitudinal $5577 \AA$ airglow variations. Can. J. Phys., 59, 1296-1307.

Colerico, M., M. Mendillo, D. Nottingham, J. Baumgardner, J. Meriwether, J. Mirick, B. W. Reinisch, J. L. Scali, C. G. Fesen, and M. A. Biondi, 1996: Coordinated measurements of $\mathrm{F}$ region dynamics related to the thermospheric midnight temperature maximum. $J$. Geophys. Res., 101, 26783-26793.

Deehr, C. S., 1969: The twilight enhancement of the auroral and nebular lines of neutral atomic oxygen. Ann. Geophys., 25, 811.

Deutsch, K. A., and G. Hernandez, 2003: Long-term behavior of the OI $558 \mathrm{~nm}$ emission in the night sky and its aeronomical implications. J. Geophys. Res., 108, 1403, doi:10.1029/ 2002JA009611.

Donahue, T. M., B. Guenther, and R. J. Thomas, 1973: Distribution of atomic oxygen in the upper atmosphere deduced from Ogo 6 airglow observations. J. Geophys. Res., 78, $6662-6689$.

Elvey, C. T., 1942: The light of the night sky. Rev. Mod. Phys., 14, 140-150.

Gulledge, I. S., D. M. Packer, S. G. Tilford, and J. T. Vanderslice, 1968: Intensity profiles of 
the 6300- $\AA$ and 5577- $\AA$ OI lines in the night airglow. J. Geophy. Res., 73, 5535-5547.

Hays, P. B., and W. E. Sharp, 1973: Twilight airglow, 1, Photoelectrons and [OI] 5577angstrom. J. Geophys. Res., 78, 1153-1166.

Hernandez, G., 1976: Lower thermosphere temperatures determined from the line profiles of the OI 17924-K (5577 $\AA$ ) emission in the night sky: 1. Long-term behavior. J. Geophys. Res., 81, 5165-5172.

Hickey, M. P., R. L. Walterscheid, and G. Schubert, 1993: A model of wave-driven fuctuations in the $\mathrm{O}\left({ }^{1} \mathrm{~S}\right)$ nightglow. Eos Trans. AGU, 74, Spring Meet. Suppl., 218.

Hickey, M. P., M. J. Taylor, C. S. Gardner, and C. R. Gibbons, 1998: Full-wave modeling of small-scale gravity waves using airborne lidar and observations of the Hawaiian airglow (ALOHA-93) $\mathrm{O}\left({ }^{1} \mathrm{~S}\right)$ images and coincident NA wind/temperature lidar measurements. J. Geophys. Res., 103, 6439-6454.

Hickey, M. P., and R. L. Walterscheid, 2001: Secular variations of OI $5577 \AA$ Airglow in the mesopause region induced by transient gravity wave packets. Geophys. Res. Lett., 28, 701-704.

Kim, Y. H., S. S. Hong, and J. L. Weinberg, 2002: Equatorial spread F found in $5577 \AA$ and $6300 \AA$ airglow observations from Hawaii. J. Geophys. Res., 107, 1264, doi:10.1029/ 2001JA009232.

Kita, K., N. Iwagami, T. Ogawa, A. Miyashita, and H. Tanabe, 1988: Height distributions of the night airglow emissions in the $\mathrm{O}_{2}$ Herzberg I system and oxygen green line from a simultaneous rocket observation. J. Geomag. Geoelectr., 40, 1067-1084.

Kita, K., N. Iwagami, and T. Ogawa, 1992: Rocket observations of oxygen night airglows: Excitation mechanisms and oxygen atom concentration. Planet. Space Sci., 40, 12691288.

McDade, I. C., and E. J. Llewellyn, 1986: The excitation of $\mathrm{O}\left({ }^{1} \mathrm{~S}\right)$ and $\mathrm{O}_{2}$ bands in the nightglow: A brief review and preview. Can.J. Phys., 64, 1626-1630.

Megill, L. R., 1960: Photometric observations of the twilight glow [OI] 5577 and [OI] 6300. J. Atmos. Terr. Phys., 17, 276-285.

Meriwether, J. W., 1989: A review of the photochemistry of selected nightglow emissions from the mesopause. J. Geophys. Res., 94, 14629-14646.

Nicolet, M., 1954: Origin of the emission of the Oxygen green line in the airglow. Phys. Rev., 93, 633 .

Ogawa, T., N. Iwagami, M. Nakamura, M. Takano, H. Tanabe, A. Takechi, A. Miyashita, and K. Suzuki, 1987: A simultaneous observation of the height profiles of the night airglow OI5577 ̊, $\mathrm{O}_{2}$ Herzberg and Atmospheric bands. J. Geomag. Geoelectr., 39, 211-228.

Schaeffer, R. C., 1975: Twilight enhancement of $\lambda$ 5577-Å airglow. J. Geophys. Res., 80, $154-160$

Schubert, G., R. L. Walterscheid, M. P. Hickey, and C. A. Tepley, 1999: Observations and interpretation of gravity wave induced fluctuations in the OI $(557.7 \mathrm{~nm})$ airglow. $J$. Geophys. Res., 104, 14915-14924.

Shepherd, G. G., J. Stegman, P. Espy, C. C. McLandress, G. Thuillier, and S. Zhang, 1999: Springtime transition in lower thermospheric atomic oxygen. J. Geophys. Res., 104, 213-224. 
Silverman, S. M., 1970: Night airglow phenomenology. Space Sci. Rev., 11, 341-379.

Smith, L. L., and W. R. Steiger, 1968: Night airglow intensity variations in the [OI] $5577 \AA$ and [OI] $6300 \AA$ A, and NaI 5890-96 ̊ emission lines. J. Geophys. Res., 73, 2531-2538.

Smith, S. M., J. Scheer, E. R. Reisin, J. Baumgardner, and M. Mendillo, 2006: Characterization of exceptionally strong mesospheric wave events using all-sky and zenith airglow observations. J. Geophys. Res., 111, A09309, doi:10.1029/2005JA0011197.

Takahashi, H, B. R. Clemesha, Y. Sahai, P. P. Batista, A. Eras, A. H. P. Chaves, B. Rossire, and J. R. Daniel, 1987: Rocket observations of the atomic and molecular oxygen emissions in the equatorial region. Adv. Space Res., 7, 47-50.

Takahashi, H., S. M. L. Melo, B. R. Clemesha, D. M. Simonich, J. Stegman, and G. Witt, 1996: Atomic hydrogen and ozone concentrations derived form simultaneous lidar and rocket airglow measurements in the equatorial region. J. Geophys. Res., 101, 40334040.

Takahashi, H., M. J. Taylor, J. H. A. Sobral, A. F. Medeiros, D. Gobbi, and D. C. Santana, 2001: Fine structure of the ionospheric plasma bubbles observed by the OI 6300 and 5577 airglow images. Adv. Space Res., 27, 1189-1194.

Torr, D. G., 1985: The photochemistry of the upper atmosphere. In: Levine, J. S. (Ed.), The Photochemistry of Atmospheres, Earth, the Other Planets, and Comets, Academic Press, Orlando.

Weinberg, J. L., and H. M. Mann, 1967: A program of ground-based studies of the zodiacal lights. In: The Zodiacal Light and the Interplanetary Medium, NASA SP-150, 3.

Yao, I. G., 1962: Observations of the night airglow. In: Yao, I. G. (Ed.), Annals of the International Geophysical Year, 24, Pergamon Press, New York.

Chiou, S. W., L. N. Hau, J. B. Nee, C. S. Jao, B. J. Wang, Y. F. Chen, W. L. Teh, S. H. Chuang, K. W. Lee, Y. C. Chou, Y. T. Lai, and W. Z. Fu, 2007: First ground observations of OI5577 green line emission over the Taiwan area. Terr. Atmos. Ocean. Sci., 18, 843-856, doi: 10.3319/TAO.2007.18.4.843(AA). 